\title{
Pacemaker Following Adult Cardiac Surgery
}

\author{
Silvero Miriam, Browne Leonardo and Solari Gabriel \\ Hospital San Juan de Dios de La Plata \\ Argentina
}

\section{Introduction}

The postoperative cardiac surgery status often determines a systolic and diastolic dysfunction, thus inducing the dependence of atrial contribution to ventricle telediastolic filling and a physiological dynamic contraction and so as to avoid ventricular segmental dyssynergia. The heart rate also plays an important role in maintaining an adequate cardiac output. Postsurgical pacemaker stimulation is useful in conduction disturbances and also helps to optimize cardiac index frequency dependent.

Another use may be the reduction or prevention of postoperative atrial fibrillation.

Before closing the chest electrode is usually placed in the right ventricle for an eventual postoperative univentricular stimulation. (Figure 1)

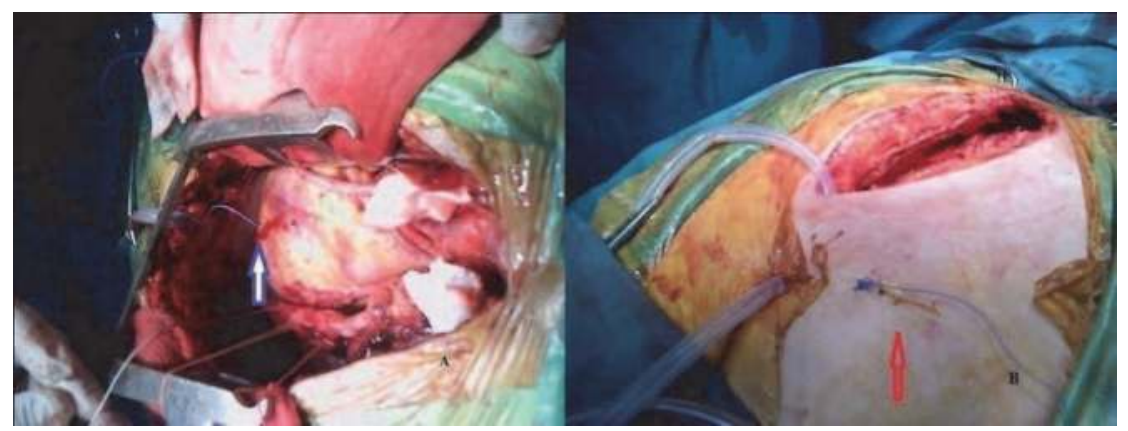

Fig. 1. A. Electrode suture wire in right ventricle. B. Wire comes out through the skin next to the incision.

In patients with left ventricular dysfunction and wide QRS complex, it may be advisable to implant another electrode in the left ventricle for biventricular pacing. (Figure 2)

In special circumstances atrial electrodes implantation would also be advantageous.

The requirement of temporary pacing (TPM) with further need of a permanent implantable pacemaker (PPM) after initial cardiac surgical procedures is usually less than $3 \%$.

The need for TPM after cardiac surgery constitutes a rare complication but it is associated with increment morbidity and an increase of resource investment. It is also true that the requirement of a permanent pacemaker implant, if indicated on time, results in a survival similar to that of other patients who did not require a placement of a permanent pacemaker. 


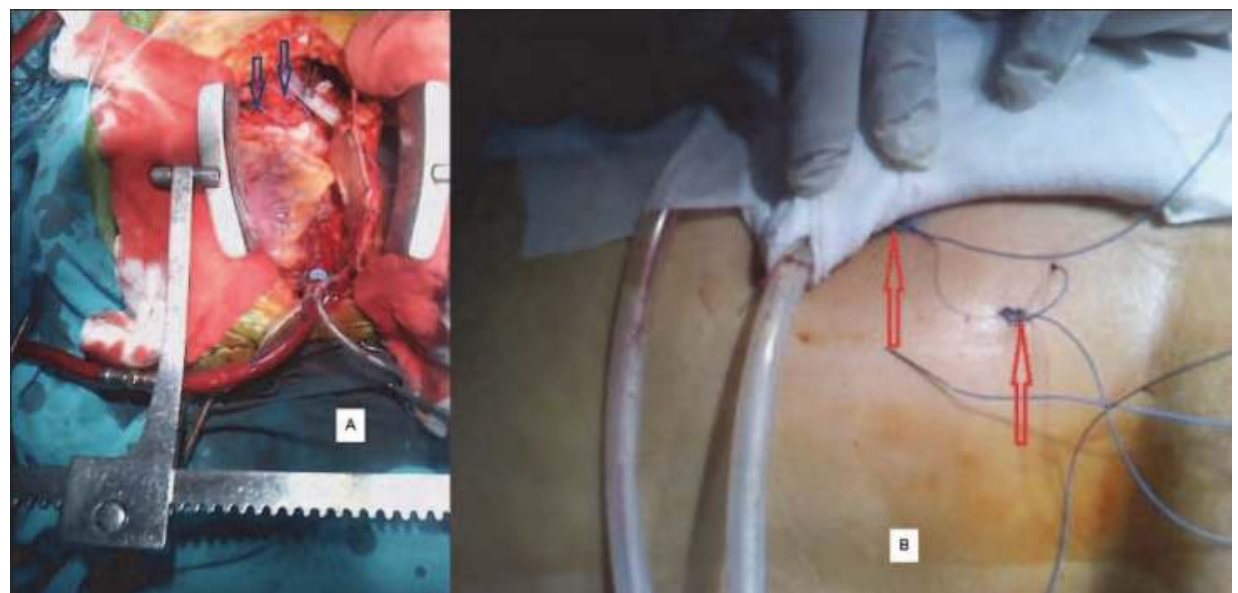

Fig. 2. A. Electrodes suture wires in right and left ventricles. B. Wires come out through the skin next to the incision.

The conduction defects associated with cardiac surgery are located at the sinus node, atrioventricular node or Purkinje His system and its branches.

The consequences depend on damage location and on whether it is an irreversible damage (such as direct traumatic injury of the conduction system during valve replacement) or temporary damage (such as ischemia observed in coronary artery bypass grafting (CABG)). First approach to the management of patients with conduction disturbances in the perioperative period during cardiovascular surgery to be taken into account are injury anatomical location and feasible aetiology. Therefore, it is indispensable to know the anatomical topography of conduction system, its relation with the rest of the cardiac structures and the irrigation type that receives from coronary arteries. For example, the appearance of complete atrioventricular (AV) block during aortic valve replacement surgery is an adverse prognostic marker, whereas the fascicular blocks are generally mild and transient. The latter occurs because in the first situation, direct injury by surgical manipulation would be involved as the atrioventricular bundle runs in the top of the wall of the septum next to the aortic annulus.

Identifying the mechanisms that cause injury to the conduction system, and recognizing risk factors may reduce its incidence, or at least prepare for this eventuality in order to make timely decisions.

In the informed consent, a percentage range of prevalence of PPM according to the patient's risk factors and type of surgery should be included. The importance of this information for the patient should not be underestimated.

\section{Prevalence of pacing after cardiac surgery}

Bradyarrhythmia after cardiac surgery may be due to injury of the conduction system during surgical manipulation in the area next to it or ischemia induced by aortic cross clamping $(\mathrm{CXL})$, or a specific coronary disease. Thus, conduction disturbances are sometimes transient because the injury can be induced by reversible ischemic damage or posttraumatic edema. This would explain well the different incidences between those who 
require TPM and those eventually discharged with a PPM. Although permanent pacemaker indications are the same as those for non-surgical patients, it is controversial to determine cardiac surgery postoperatory timing of PPM implantation.

\subsection{Temporary pacemaker}

Temporary epicardial electrodes are routinely placed in patients after cardiac surgery, but position of ventricular leads and use of atrial leads are not uniform. There are recommendations, but no protocols.

The decision of to whom and where to place electrodes for subsequent pacing is formalized in some medical centers, in others is a discretionary decision between team intervening for each patient.

In CABG surgery has been compared sutured wires in right atrium, in left ventricular apex, in right ventricular apex, and right ventricular outflow tract before cardiopulmonary bypass entrance. In postoperative period, comparison of the groups showed that the addition of atrial activation during ventricular pacing resulted in higher cardiac indexes, higher systolic blood pressures, lower central venous pressures, and similar pulmonary arterial pressures. Right ventricular outflow tract pacing resulted in higher cardiac index than left ventricular apical pacing in patients with stenosis of the left anterior descending coronary artery (DCA) in $90 \%$ or more, while left ventricular apical pacing produced higher cardiac index in the absence of DCA lesion.

CABG intervention is described as a type of cardiac surgery less damaging to the conduction system and even so it may have an incidence of TPM of $45 \%$ at the end of surgery, but the number of patients who are discharged with PPM is significantly lower.

Must there be a different protocol for the placement or not of epicardial electrodes when the CABG is performed with cardiopulmonary bypass (ONCAB) or without it (OFCAB)?

The incidence of PPM is nearly the same in both cases: $5.5-6 \%$ for OPCAB and $6.8 \%$ for ONCAB. Where is the significant difference? Mean duration for TPM pacing is longer in ONCAB. Another point is that ONCAB has higher incidence of atrial fibrillation as pacing indication. The need for pacing before chest closure accurately identifies coronary patients who will require postoperative pacing after OPCAB or ONCAB.

Is routine use of temporary epicardial pacing wires unnecessary and must their use be limited?

It can also happen that a patient exits the surgery room without TPM and then needs to be paced in the recovery room. High level evidence conclusions are not yet found.

Patients undergoing CABG not including off-pump surgery, without a preoperative pacemaker, and no pacing wire placement present an incidence of $8.6 \%$ of pacing during the postoperative period. Significant predictors for PPM on multivariate analysis are diabetes mellitus, preoperative arrhythmia, and pacing utilized to separate from cardiopulmonary bypass (CPB).

Valve surgeries, ascending aorta or intracavitary congenital interventions have higher incidence of TPM than CABG, and the gap finally requiring PPM between them is narrower.

\subsection{Permanent pacemaker (Table 1)}

Each year approximately $5 \%$ of 100,000 patients, who are undergoing cardiac valve surgery in the United States, will require postoperative PPM implantation before hospital discharge. Several studies with long list of patients, show concern about this issue. 
Prevalence differs according to the type of surgery. In a retrospective review of 5,942 patients who underwent open-heart surgery to resolve acquired heart disease, it was observed that $2.1 \%$ of patients required PPM postoperatively; $4.6 \%$ of them underwent predominantly valve surgery, and $0.6 \%$ CABG surgery (Goldman, 1984). In a study of 10,421 patients a PPM prevalence of $0.4 \%$ to $1.1 \%$ after CABG, and 3.0 to $6.0 \%$ after valve operation was found. (Gordon, 1998)

Compared to the past, the incidence of post operatory PPM implantation decreases year after year due to improvements in surgical techniques, technological innovations and understanding of the mechanisms of injury that generates the arrhythmia. Paradoxically, the total number of PPM implanted is higher. As an explanation, we can say that severe ischemic heart disease (NYHA Class III-IV) in younger and older patients with longer life expectancy is increasing. In undeveloped countries there is also an increase in the population and in the incidence of rheumatic fever with valves affectation.

Reoperation, multivalvular, combined, complex surgeries (as Bentall-De Bono procedure), and myxomas ablation, among others have higher rates of PPM. On the other hand, it also appears that using valve repair techniques instead of replacement decreases its prevalence. In heart transplantation, the incidence is between 0 and $5 \%$, but with the expansion of the inclusion criteria of donors, the percentage could attain more than $20 \%$ (older age donors). If tricuspid valve replacement or repair is included with another cardiac surgery, high incidences of PPM up to $28 \%$ can be reached. In the last two decades, more isolated tricuspid replacements have been performed (Infective endocarditis in intravenous drug users).

\begin{tabular}{lll} 
Author & $\mathbf{\%}$ & Surgery \\
\hline Gordon,1998 & $0,4-1,1$ & CABG \\
Gordon,1998 & $3-6$ & VS \\
Erdogan,2006 & 4,1 & AVR \\
Imren,2008 & 2 & CABG \\
Goldman,1984 & 0,6 & CABG \\
Goldman,1984 & 4,6 & VS \\
Emlein,1993 & 0,8 & CABG \\
Del Rizzo,1996 & 1,3 & ALL \\
Ben Ameur,2006 & 4 & VS \\
Schurr,2010 & 4 & AVR \\
Nardi,2010 & 3 & AVR \\
Merin,2009 & 1,4 & ALL \\
Limongelli,2003 & 3,2 & AVR \\
Berdajs,2008 & 4,2 & MV \\
Meimoun,2002 & 2,6 & MV \\
Ashida,2000 & 6.7 & VS \\
\hline
\end{tabular}

$\mathrm{ALL}=$ all type of cardiac surgery; $\mathrm{AVR}=$ aortic valve replacement; $\mathrm{CABG}=$ coronary artery bypass grafting; $M V=$ mitral valve surgery; VS = valve surgery.

Table 1. Postoperative permanent pacemaker. Prevalence.

The reversibility of conduction defect continues recovering not just in the immediate postoperative period but also in the short, medium and long term. Thirty per cent in those 
with a narrow escape QRS, and $18 \%$ in others with wide QRS, no longer need the pacemaker during follow-up. Up to one third of patients recover at late follow-up.

\section{Damage mechanisms in the conduction system during cardiac surgery}

The main physiopathological mechanisms involved in the genesis of AV conduction disorders are myocardial ischemia, direct surgical injury,inadequate cardiac protection during surgery, and cardiac depressant medication (beta blockers, calcium blockers, etc.). Mechanical trauma to the conduction system, arising secondary to valve operation, myomectomy for hypertrophic obstructive cardiomyopathy, or repair of ventricular septal defect, appears to be the most frequent cause.

Alternatively, ischemic injury of the sinoatrial node or conduction system might occur during any cardiac procedure as a result of inadequate myocardial protection during surgery time. Then, there are three postulates:

1. Operative procedures performed in close physical proximity to the sinoatrial or atrioventricular nodes or the His branch bundle.

2. Extensive coronary artery disease which compromises myocardial protection during intraoperative procedure, specially related to cardiopulmonary bypass and aortic crossclamp duration.

3. Poor myocardial protection even without coronary disease.

(1) Risk of physical damage is increased in conduction system in patients who have repeated valve operations, in patients who underwent multiple valve replacement, and during debridement or reconstructive operation for active endocarditis. Similarly, debridement of a calcified aortic annulus after excision of the aortic valve might be the source of significant trauma to the conduction system. The surgical procedures added to CABG or aortic valve replacement (AVR); such as mitral valve replacement (MVR), sub aortic stenosis (SAS) resection, and ventricular septal defect (VSD) closure, are postulated as predict factors for the occurrence of postoperative AV conduction disturbances. This is not surprising: association between surgical manipulations at the fibrous skeleton of valves or septal wall, the immediate anatomical vicinity of the AV node, and the proximal conduction bundle entail a great possibility for the need of a PPM. These procedures have long development times and add to the manipulation risk, the factor mentioned in the second item (2), the risk of inadequate myocardial protection.

It has been suggested that patients with aortic valve disease have histological abnormalities of the conduction system because of elevated intraventricular pressures thus generating ischemia and degenerative disease of the conducting system. These tissues are more vulnerable to manipulation.

(2) In ischemic heart disease with involvement of the coronary artery supplying the conduction system, until it is revascularizated, there is a latent possibility of bradyarrhythmia or blockage. During surgery, the so-called "reperfusion arrhythmias" with the re-establishing of the flow in territories that had prior deficit can occur. If there is right dominance and the right coronary artery is obstructed, thus compromising blood septal flow with conduction abnormalities, which promote high incidence of need PPM, both in CABG as AVR regularly occur.

(3) When not performing an adequate myocardial protection adverse events are developed such as severe arrhythmias, ventricular failure requiring high doses of inotropic drugs or circulatory support, prolonged weaning from $\mathrm{CPB}$, metabolic disorder, etc. 
One must realize the mistake: temperature, cardioplegia type, long CXL time periods, appropriate surgical indication, and optimization of the patient status or several of these causes. Each patient deserves deep investigation.

\section{Preoperative risk predictors of permanent pacemaker insertion}

The preoperative identification of a high-risk subset of cardiac surgery patients who may require permanent pacing has an important implication to decide the number and location of temporary epicardial pacing wires to implant at the time of surgery. Their postoperative removal can cause bleeding, cardiac tamponade (cavity rupture), bypass graft injury, infection and other complications, but in many patients the absence of epicardial electrodes also carries a risk associated with delayed treatment of the bradyarrhythmia. It is important to know the factors to do the best in each case.

In relation to demographic and clinical features of patients, descriptive studies agree that the preoperative risk factors are: absence of preoperative sinus rhythm, female gender, advanced age ( $\geq 65$ years), dense calcium in the aortic annulus, endocarditis, unstable angina, compromised septal blood flow, ventricular dilatation, renal failure, hypertension, some kind of drug medication and end-systolic left ventricle diameter.

Infective endocarditis is a particular condition that usually involves a sepsis state or incipient multiorganic failure involving heart and its structure, suffering hypoperfusion as a consequence of inability to keep adequate consumption-availability balance tissue oxygen. The conduction tissue is no exception to this rule: no perfusion, no proper function.

Regarding the preoperative rhythm, patients with first degree atrioventricular block (AVB) or fascicular block have higher incidence of permanent post operatory AVB. In valve surgery, the biggest risk is present in patients with right bundle branch block (RBBB). The incidence of left bundle branch block after aortic and mitral valve surgery is high, and having the previous RBBB, a trifascicular block develops more easily. However in coronary surgery, left bundle branch block (LBBB) is a more potent predictor of postoperative pacemaker need, than RBBB. (Table 2)

\begin{tabular}{|c|c|}
\hline CABG & VALVE SURGERY \\
\hline LBBB & RBBB \\
AF & AF \\
RBBB & BIFASICULAR BLOCK \\
BIFASICULAR BLOCK & LBBB \\
\hline \multicolumn{2}{|c|}{ AVB } \\
\hline
\end{tabular}

$\mathrm{AVB}=$ atrioventricular block $\mathrm{AF}=$ atrial fibrillation $; \mathrm{CABG}=$ coronary artery bypass grafting; $\mathrm{LBBB}=$ left bundle branch block; RBBB = right bundle branch block.

Table 2. Preoperative arrhythmias needed more pacing in the postoperative period according to the type of surgery.

In controversy, some authors found no additional relationship with age, gender, kind of valve disease, anemia, and use of digitalis or angiotensin converting enzyme inhibitor, preoperatory conduction disturbances, myocardial infarction (MI) or coronary arteries affected. 
More meta-analysis studies should be made regarding these issues. The analysis can be adjusted by age group, type of surgery, previous systemic diseases, preoperative cardiac diseases, etc., if significant results cannot be obtained, a risk score must be built for each medical center.

There are attempts to validate risk scores as Koplan B,1993 validated with 4694 patients who underwent valve surgery :prediction Group $n=3,116$ and a validation Group $n$ $=1,578$. The exclusion criteria were patients who had an indication for PPM or an implanted cardioverter defibrillator (ICD) preoperatively, or who died within six days after surgery. Postoperative ICD implantation were considered to have a PPM only if they also had an indication for permanent pacing independent of their need for an ICD; otherwise they were classified in the no pacemaker group. The decision to implant a permanent pacemaker after surgery was at the physician's discretion in agreement with the current American College of Cardiology/ American Heart Association guidelines for permanent pacing. This study utilized demographic data, electrocardiogram (ECG), and surgical characteristics to predict the need for permanent pacing after cardiac valve surgery. (Table 3 and 4 )

\begin{tabular}{ll}
\hline ECG Points & Points \\
\hline Right bundle branch block & 2 \\
Left bundle branch block & 1 \\
PR interval >200 & 1 \\
\hline Multivalve surgery & \\
\hline Tricuspid valve include & 2 \\
Tricuspid valve not include & 1 \\
\hline Others & \\
\hline Age $\geq 70$ & 1 \\
Prior valve surgery & 1 \\
\hline
\end{tabular}

ECG $=$ electrocardiogram.

Table 3. Risk score to predict PPM after valve surgery. (Koplan B, 1993)

\begin{tabular}{cc} 
Score Points & \% PPM \\
\hline 6 & 50 \\
5 & 36 \\
4 & 21 \\
3 & 12 \\
2 & 8,7 \\
1 & 5,2 \\
0 & 1,9 \\
\hline
\end{tabular}

Table 4. Percent of patients in the validation group who required PPM. (Koplan B, 1993) 
The risk score allows patients to know preoperatively the likelihood of a PPM and this should therefore be notified.

\section{Intraoperative risk factors}

It is crucial to know all perioperative risk factors, so that the patient knows and is aware of it in the preoperative informed consent. Counseling about the risk is part of medical ethics.

Gordon R. (1998) analyzed one hundred and thirty-four variables in a data base of 10,721 patients and identified those who had cardiac operations. All those variables are considered to be potential risk factors to date. (Figure 3)

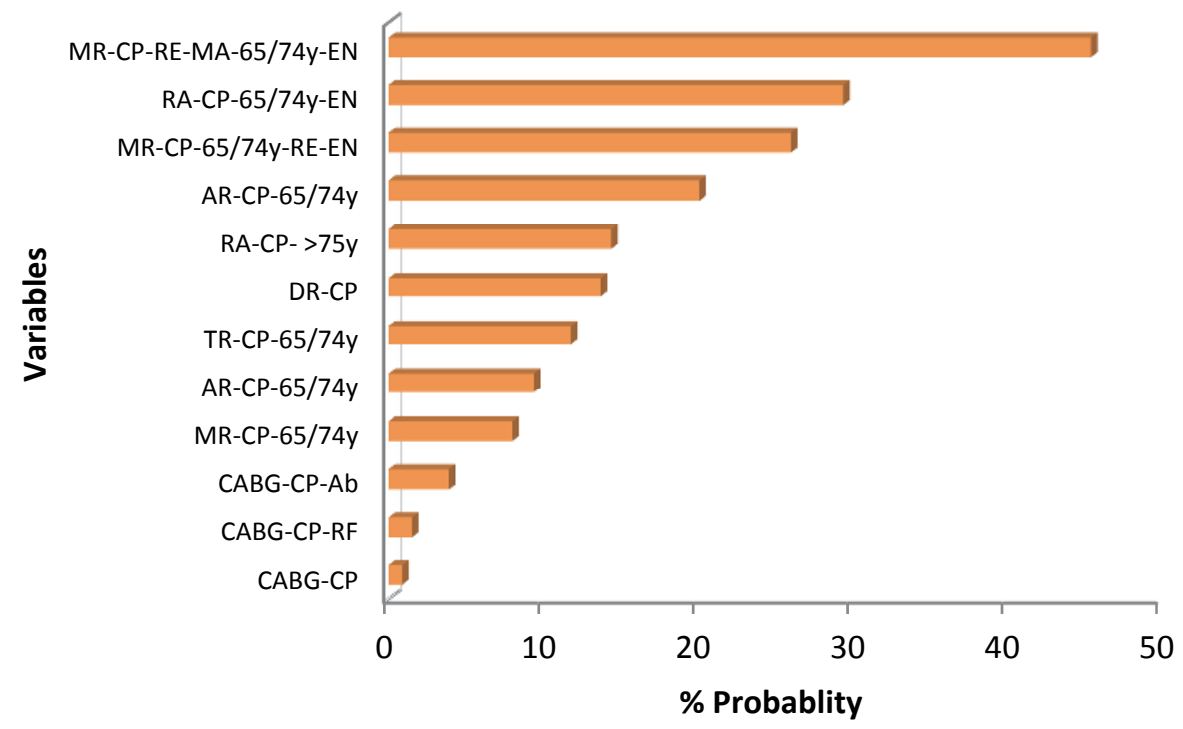

$\mathrm{Ab}=$ ablation; $\mathrm{CABG}=$ coronary artery bypass grafting; $\mathrm{CP}=$ cold cardioplegia;

$\mathrm{DR}=$ Double valve repair or replacement; $\mathrm{EN}=$ active endocarditis; $\mathrm{MA}=$ mitral valve annulus reconstruction; $\mathrm{MR}=$ mitral valve repair or replacement; $\mathrm{AR}=$ aortic valve repair or replacement; $\mathrm{RE}=$ reoperation, $\mathrm{RF}=$ preoperative renal failure; $\mathrm{TR}=$ triple valve repair or replacement; $\mathrm{Y}=$ years .

Fig. 3. Predicted probabilities of permanent pacemaker requirement based on common operative variables. (Gordon R, 1998)

We can see in Figure 3 that trauma is the most frequent damage mechanism. Reoperation is repairing tissue which was manipulated and suture previously. Endocarditis is an inflammation status; it presents friable places, especially right and left fibrous trigones (Figure 4) whose boundary structures (valves themselves, coronary arteries and conduction system) are extremely close; the surgeon must work there. Older people have less tissue reconstructive capacity. In this score validation, the variable included as myocardial protection damage mechanism is cold cardioplegia, in this last item, the debate is still now open. 


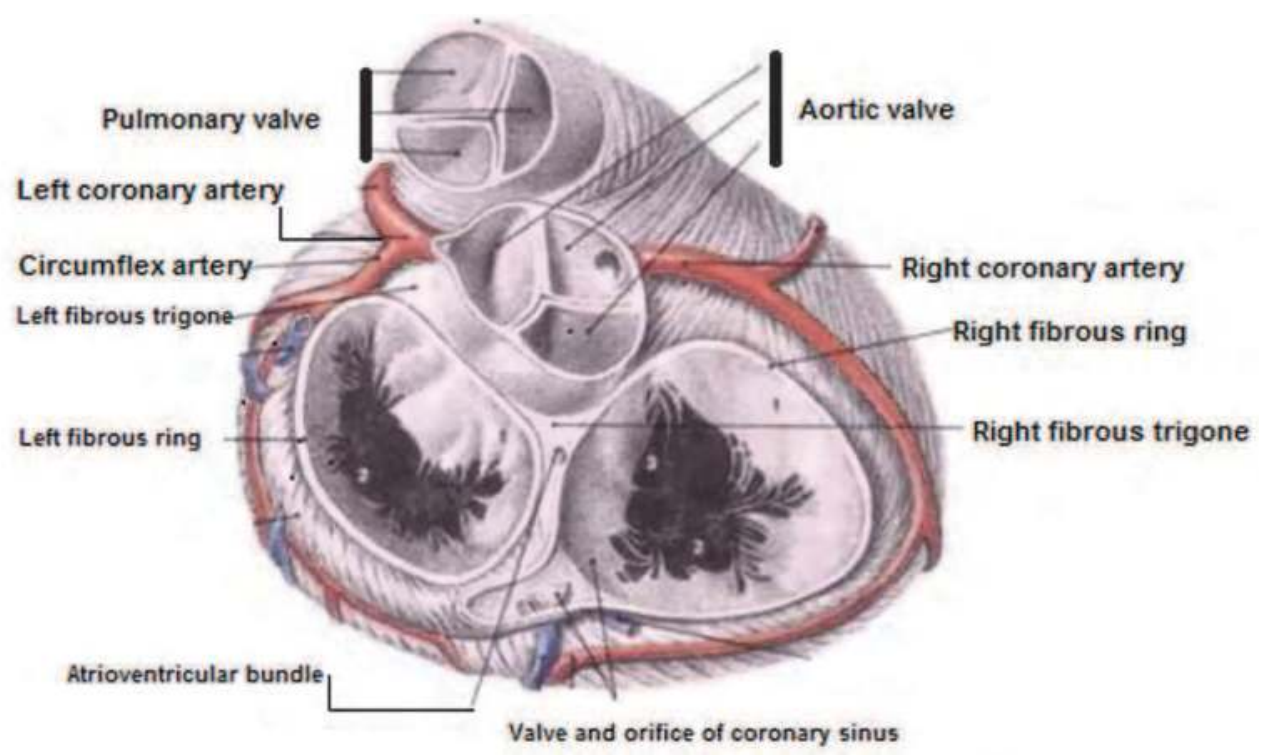

Fig. 4. Fibrous cardiac trigones

\subsection{Valve surgery}

So far, no studies determining in high value evidence what predictive risk factors are the strongest at the time of valve replacement might have forecasted postoperative PPM implantation. Each patient, each type of disease, intraoperatory and postoperatory events as well as decisions; are especially different and determine multiple variations.

\subsubsection{AVR}

Conduction abnormalities are commonly associated with aortic valve disease. During the 1960s, the incidence of complete heart block after AVR approached 13\%. Recent reports indicate that the incidence has decreased to approximately $6 \%$.

Preoperatory AVR risk factors are: female gender, age $\geq 65$ years, systemic hypertension, myocardial infarction, conduction disturbances, greater preoperative left ventricle endsystolic diameter, poor left ventricle ejection fraction $(<35 \%)$, left atrial enlargement, left ventricular septum hypertrophy, calcified aortic root bicuspid aorta, annular calcification and aortic regurgitation.

Intraoperative factors are: additionally surgical procedure as $\mathrm{CABG}$, redo surgery, $\mathrm{CPB}$ time, cross clamp time, stentless bioprosthetic and valve size.

The inserted wrong valve size chosen not only predisposes to PPM, but it also could need to be removed because the aortic disease becomes worse than before surgery.

Postoperative factors: electrolyte imbalance, myocardial infarction, cardiac arrest. All these situations that affect the consumption/availability of tissue oxygen, if not resolved, degenerates in an inability of physiological function on organs and systems. Cells cannot get oxygen, nor membranes achieve exchange.

Adding conduction system hypoperfusion and malfunction it is clear how conduction failure. 
Persons aged $\geq 75$ years in the coexisting aortic valve surgery with $C A B G$, determine the double risk of PPM.

However, discussion exists as to whether surgery intended to this subset reflects a costeffective approach to attaining life quality since it has high mortality (more than $5 \%$ ).

Significant preoperative risk factors for early mortality (first week) include poor left ventricular function and preoperative pacemaker insertion. Predictors of late mortality (first month) include chronic obstructive pulmonary disease and urgency surgery.

Feature and valve configuration, might predispose to mechanical trauma of the conduction system during AVR: alteration of length of the membranous septum, calcification in the region of the atrioventricular bundle and its branches, and bicuspid valve; the latter can be congenital or fused by disease. (bicuspidization).

A pathologic study of the cardiac conduction system was performed in specimens that had undergone AVR, searching the impact of postoperative compression exerted by the valve, the suture and calcium ring.

Evidence found about higher incidence of traumatic recent lesions was: septum length less than $5 \mathrm{~mm}$, mechanical injury to the conduction tissue attributed to residual deposits of calcium (its manipulation during surgery), and congenital bicuspid valve.

Especially in aortic regurgitation, the endocardium marked fibrous thickening in the left ventricular septum can cause degeneration of the driving system which run through it.

This thickening is caused by regurgitated blood flow that strikes the septum.

The intimate relationship between conducting tissue and prosthesic valve suggests that direct trauma at time of surgery might be involved: suture injury, pressure from residual calcic material, and impingement prosthesic valve against conduction system.

(Elahi M., 2006) introduces us to a new question: type and size of prosthesis influence in the incidence of implantation of PPM in AVR? In his research of 510 AVR isolates, smaller aortic prosthesis size $(<21 \mathrm{~mm})$ was identified as a significant predictor of hospital mortality $(\mathrm{P}<0.05)$ demonstrating that stentless valves required longer bypass and cross clamp times. This suggests that prevalence of PPM seems to be dependent on the size and type of prosthesis. PPM incidence is twice in a group with stentless valve $(18 \%$ vs. $9.1 \%$; $P=0.01)$.

In Providence Hospital in Michigan analyzed predictors in a study of 214 AVR with $6.3 \%$ incidence of PPM .There was no relationship with the type of valve. (Mechanical vs. Bioprosthetic) nor with its subtypes (stentless vs. stented).

(Totaro P., 2000) demonstrated that continuous rather than interrupted sutures were more often associated with postoperative AV conduction defects and PPM implantation $(17.5 \%$ vs. $2.2 \%)$, but the two groups were not homogenous for age and cross clamp time.

¿Required time of valve placement, or its constituent material, or degree of degeneration of the aortic annulus, or the size of valve that has been decided to implant? ¿Wich is the variable? Further clinical trials, multicenter studies and meta-analysis are needed.

\subsubsection{Trans-catheter self-expanding aortic bioprosthetic implantation (TAVI)}

This last decade has innovated AVR technique with trans-catheter self-expanding aortic bioprosthetic implantation. It is performed while the heart is still beating without the need for a bypass or sternotomy. The procedure may be retrograde, performed via the transfemoral or subclavian or through a transapical approach. (Figure 5)

Often used in patients over 75 years with credibility as a valuable alternative to non surgical option. However, these patients are often affected by severe iliac-femoral arteriopathy too, rendering the transfemoral approach unemployable. This new technique does not escape PPM risk. The incidence is nearly 33\%.It is extremely lofty. To address this high rate of complication it is necessary to carry out a careful evaluation of the aortic replacement with 
this technique. Pre-existing right bundle branch block is an independent predictor of complete AV block after TAVI.

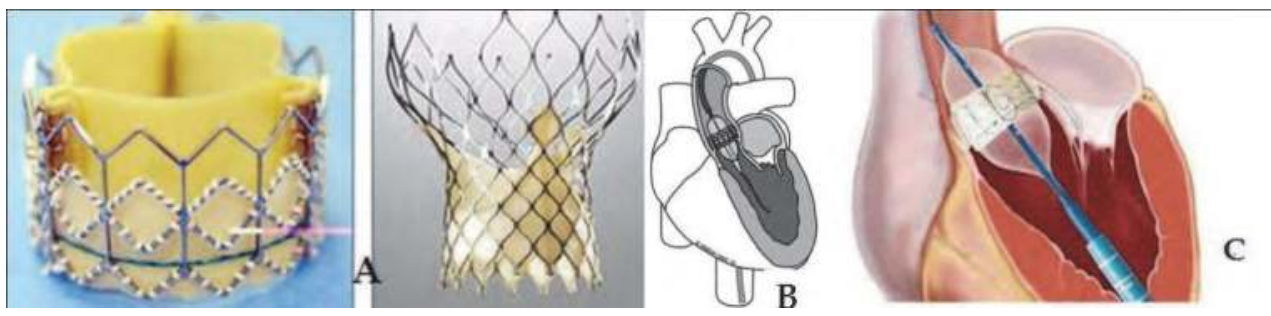

Fig. 5. A TAVI valves. B Transarterial approach. C Transapical approach.

In a European multicenter study including 16 centers, four hundred and forty four patients with a mean age of 82 years, only hold a post-intervention PPM incidence of $11,8 \%$. The interesting point about this research is the inclusion of two different types of prosthesis and also different approaches. The bias of this analysis may arise from the variety of independent variables. However, the final outcome the post-intervention PPM implantationis lower, improving the results of those studies that use a single brand of valve or only one implantation approach.

Choice of prosthesis, approach election, indication time, patient's clinical status? What items improve incidence? We must find more specific evidence.

Another question to be answered: which is the appropriate technical surgery in elderly patients or must medical treatment be taken into account?

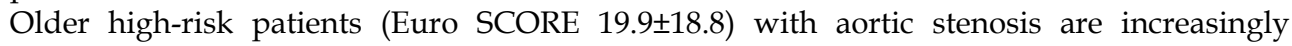
referred to TAVI but a subgroup of these cases is unsuitable for this and so conventional AVR is undertaken. The incidence of PPM is 7\% (lower than TAVI). But re-operation for bleeding, renal failure, tracheotomy and sternal wound infection are frequent.

\subsubsection{MVR}

There are specific factors related to PPM in MV surgery. (Table 5)

Factors

\begin{tabular}{l}
\hline \multicolumn{2}{c}{ Preoperatory } \\
Pulmonar hypertension \\
Antiarrhythmic drugs \\
Sotalol \\
Digoxin \\
Mitral valve stenosis \\
Mitral annular calcification \\
\hline Cross clamp time \\
Mitral valve replacement \\
Combined surgery(AVR-CABG) \\
Sternotomy approach \\
Reoperation
\end{tabular}

Table 5. Specific factors related to PPM in MV surgery. 
The mitral valve apparatus is anatomically close to the atrioventricular conduction system, particularly the posterior-medial commissure of the anterior mitral leaflet, which lies close to the atrioventricular node (Figure 4).

Right now, it is important to refer to the different irrigation received by the AV node; in more than $70 \%$ of individuals it comes from the right coronary artery and for the rest, from the left. The coexisting coronary artery disease should not be underestimated. This should be expected in a well differentiated manner against the possibility of ischemia of conduction system during the MV surgery. Considering the topography of fibrous mitral and tricuspid rings the variants are:

1. The artery passes along the left lateral margin of the superior process and after reaching the proximal part of the annulus fibrosus of the posterior leaflet of the mitral valve the artery passes just lateral to the postero-medial commissure.

2. The artery runs in the middle of the space between the mitral and tricuspid valve.

3. The artery passes just adjacent but not in contact to the annulus of the septal leaflet of the tricuspid valve.

Trauma caused by manipulating the valve apparatus could result in ischemia because adjacent coronary artery flow is restricted by suture tug. The same manipulation is done around AV node. Tight suture can damage it. Face situation adding factors that become a vicious circle. The circumflex artery is the most affected by subocclusion. There is a relationship between iatrogenic circumflex lesions and coronary dominance, but no difference exists between replacement/repair.

Mechanisms underlying postoperative AVB following mitral valve replacement or annuloplasty are very interesting to research. In dry dissected human hearts, the AV node artery was discovered to run close to the annulus of the mitral valve in $23 \%$ of patients.

Reconstruction has recently become the technique of choice in the treatment of patients with mitral regurgitation of degenerative origin. This surgical technique is more complex and sometimes results in longer ischemic times. The longer intraoperative ischemia has been postulated as being responsible for the postoperative incidence of the AV node block in this type of intervention.

The extended transseptal approach provided a better exposure of the mitral valve compared to conventional approach. The operative times and the incidence of mortality and complications were similar to conventional technique. About $4.8 \%$ of patients required PPM.

Predictors of PPM in mitral valve repair using Carpentier's techniques: $23 \%$ perform AVB but is transient, and partially or completely resolves before the seventh postoperative day. No mitral type procedures including anterior versus posterior leaflet repair is related to AVB. Systemic hypothermia during surgery is the only independent predictor. Only $2.6 \%$ require PPM.

Surgery involving the aortic and mitral valves can increase the trend to receive PPM over three times, as an example $13.3 \%$ vs. $5.8 \%$.

In the same manner as the AVR surgeries goal is to reduce the complications in elderly patients using TAVI, for mitral valve surgery also investigates the same goal: a minimally Invasive (right lateral minithoracotomy) versus sternotomy. The minimally invasive approach led to longer duration of surgery, cardiopulmonary bypass, and cross-clamp time. By sternotomy the number of postoperative arrhythmias and pacemaker implants was higher. In this surgical technique, long surgery times as cause of inadequate tissue perfusion, which is an important factor for severe postoperative arrhythmia, are discarded. 
In this occasion, the traumatic would be the only damage mechanism. Validation of this statement could only be done on absolutely homogeneous group (Euro SCORE, disease severity, surgeon, perfusionist, anesthesiologist, etc).

The results on the incidence and risk factors for PPM according to the region where you get the results must be carefully analyzed. The bias is found for example between Latin America and North America. In the former, the main underlying valve disease for surgical indication is rheumatic fever while in the latter is fibroelastic mucopolysaccharide deficiency.

\subsection{Redo surgery}

The incidence to permanent pacemaker need after repeated cardiac surgery has approximately a fourfold increase. Factors commonly found are surgeries that involve two valves, preoperative endocarditis, increasing number of reoperations, the degree of hypothermia during cardiopulmonary bypass and advanced age. Additional univariable predictors included are $\mathrm{CPB}$, aortic cross clamp increased time, and aortic valve replacement. (Lewis J, 1998) studied 558 consecutive patients undergoing at least one repeated cardiac operation: in this group, 54 patients $(9.7 \%)$ required a permanent pacemaker. The need for a permanent pacemaker after reoperations did not result in significant long-term impairment of functional status or longevity compared with those who did not require a permanent pacemaker.

\subsection{Myxomas}

Atrial myxomas are the most frequent primitive cardiac tumors $(50 \%)$. They appear between 30 and 60 years old, predominantly in women, and the most common location is the left atrium (75\%) followed by the right atrium (15-20\%) Only $4 \%$ are located in the ventricles. In $90 \%$ of cases there are solitary tumors but may be part of familiar syndromes (Carney).

In this case, there are at least two myxomas and the right atrium is the most affected cavity. Its symptoms are usually due to cavity obstruction. By their anatomical location, they may affect the conduction system and this can also be a symptomatic manifestation.

Not many publications deal with the need for PPM after the resection of these tumors. If the myxoma is located in the atrial septum, it is directly related to the need for PPM.

There are approximately 2.6 up to $18.8 \%$ of incidence of PPM.

\subsection{Congenital heart disease surgery}

The most common cardiac diseases that reach adulthood with surgical indication are atrial and ventricle septal defect, coarctation of aorta, persistent ductus arteriosus, bicuspid aortic stenosis, subaortic stenosis and ectasia of the aortic annulus in Marfan syndrome. The aortic and sub aortic stenosis was previously exposed in 5.1.1.

Not all congenital diseases that reach adulthood and are resolved after surgery can have endocardial PPM implantation. Epicardial pacing systems appear to have a higher incidence of lead failure predominantly in ventricle lead and are significantly less durable. This is a problem to be solved in each particular situation of the patient's evolution (Ebstein disease). After congenital surgery, the recovery pacemaker's dependence occurs in $10 \%$ of patients with AVB after mid-term follow-up (40 days average).

Post-operative result in congenital heart diseases with septal defect is often impaired by the occurrence of disorders in atrio-ventricular conduction. 


\subsubsection{Septal defects}

Interventricular communication (IVC) in adults is rare, most cases close spontaneously (before 10 years) or are surgically corrected during childhood. Its evolution depends on its location and size. There are 4 types: perimembranous, infundibular, anterior and trabecular core. The perimembranous and trabecular are the most frequent representing $90 \%$ of cases. The perimembranous persists for a longer term and constitutes $10 \%$ of adult congenital heart disease. The defect is located in the membranous septum with possible extension to the muscular region. Among the electrical abnormalities secondary to surgery $2 \%$ of complete atrioventricular block occur in immediate postoperative period, but it may appear after discharge as paroxysmal atrioventricular block. Incidence of PPM is nearly $2.5 \%$. The defect near the conduction system and also the one with a larger diameter $(\geq 1 \mathrm{~cm})$ are more likely to lock AVB followed by PPM. It should be kept in mind that larger defects require patch closure and sutures cover extensive zone of tissue. Inter-auricular communication (IAC) is the most common congenital heart disease predominant in adult (40\%), with a female predominance and can manifest at any age. There are four types of IAC ostium secundum (most common defect at the atrial septum, i.e. foramen ovale type) sinus venosus (upper and lower), coronary sinus type and ostium primum type. The symptoms are: breath, atrial arrhythmia, cardiomegaly, right branch block bundle, paradoxical embolism or pulmonary vascular disease

The chronic course (diagnosed and untreated or non-diagnosed) is associated with left atrium increasing diameter, myocardial loss, and generalized conduction abnormalities, which favors the installation of sustained atrial fibrillation. Treatment in patients over 40 years is often cause for discussion.

Closure performed by surgery or percutaneous approach with Amplatzer TM septal occluder (ASO) can be indicated at any age with the exception of pulmonary hypertension. Percutaneous closure can be the method of choice in isolated ostium secundum with appropriate edges, but it is an expensive procedure. Surgery is relegated to ostium secundum with defective edges or multi fenestrated. Surgical treatment gives better results than percutaneous technique and medical treatment. Septal occluder implant treatment shows superior results to surgery respect to some complications, but they were not significant in adults under 40 years.

There is certainly nothing wrong with continuing to do surgery in countries where the resources are limited. After surgical closure, atrial arrhythmias occur between $12 \%$ and $14 \%$ of patients (70\% atrial fibrillation). PPM following AVB is related to age (>50 years),reoperation, cross clamp and CPB time. IAC complex types, simultaneous mitral insufficiency repair or other congenital procedure imply long surgery times.

\subsection{Ascending aorta surgery. Marfan syndrome. Bentall- De Bono intervention}

The intervention on the ascending aorta is always a challenge. The pathologies of surgical indications are: dilation $(>5 \mathrm{~cm})$, aneurysm, primary or secondary dissection of the artery (dilatation or aneurysm). These diseases may include in its pathophysiology aortic valve insufficiency. Combined intervention with artery and valve repair has a high index of AV block. The origin of the aneurysm may be degenerative (cystic, ecstatic, atherosclerotic), traumatic (blunt, penetrating, surgical and diagnostic), inflammatory, infectious, mechanical, dissecting and congenital. The most common congenital cause is Marfan syndrome which usually has annular aortic ectasia. The fundamental cause is a cystic media necrosis with high incidence of dissection and rupture. 
Annulo-aortic ectasia is a dilation of the aortic root with the involvement of the Valsalva sinuses. In 1968, Bentall and De Bono proposed to replace aortic valve, Valsalva sinuses and the ascending aorta with a composite tube graft with aortic valve prosthesis. Also aortic root homografts are a valid alternative, specially in infection status; the main advantage of this therapy is that permanent anticoagulation is not needed. (Figure 6) Consequently, coronary ostiums have to be reimplanted on the prosthetic tube. This surgery is an adult cardiac surgery more technically complex and has a high incidence of complications such as bleeding, complete AVB, hemiparesis and high mortality. The causes of AVB are the extreme proximity to the conduction system, extreme hypothermia while the $\mathrm{CPB}$ is performed and/or circulatory arrest. The danger of inadequate perfusion and ischemia is aggravated because CPB is usually very prolonged ( $\geq 120$ minutes). The incidence of PPM is about 5 to $14 \%$.
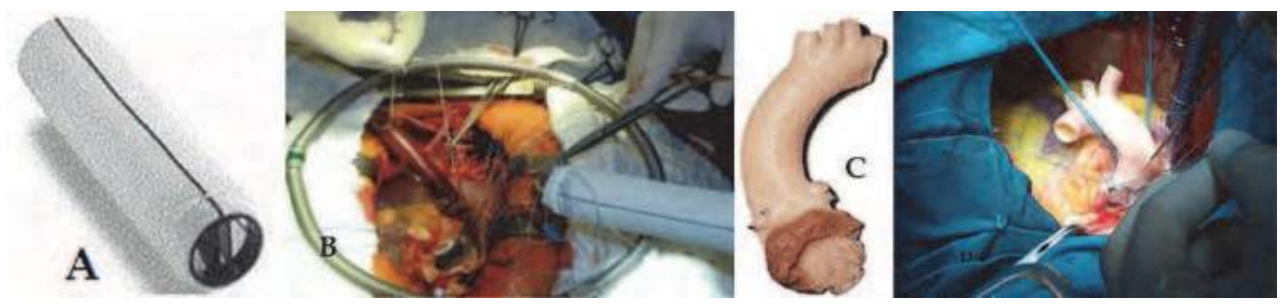

Fig. 6. A.Tube graft with aortic valve prosthesis, B. Bentall De Bono surgery. C. Aortic Homograft , D. Bentall De Bono surgery with homograft

\subsection{CABG- myocardial protection}

With longer CBP times, there is a lower myocardial protection quality. Duration bypass > 120 minutes is a significant predictor of long-term pacemaker dependency. More number of vessels bypassed in CBGA derives in longer CXL and CPB times, resulting in higher risk for PPM.

If myocardial protection is inadequate and uneven, it leads to perioperative myocardial infarction and low output syndrome, exacerbating postoperative conduction disturbances. Although some evidence exists to suggest that the type (Crystalloid-Blood), the way (Antegrade-Retrograde), the temperature (Warm-Tepid-Cold) and the time delivery (Continuous-Discontinuous) of cardioplegia increase the risk of PPM insertion, reports are contradictory.

Normothermic cardioplegia is associated with a marked decrease in new and permanent conduction disturbances and CK-MB postoperative release. This suggests that a significant factor in the pathogenesis of conduction blocks is cold-related injury.

Cold blood cardioplegia represents a risk factor for PPM and this finding might be related to differences in delivery and not to cardioplegia composition.

It seems that continuous delivery provides improved myocardial protection and reduces the incidence of postoperative conduction disturbances.

Retrograde cardioplegia provides better results in venous sinus oxygen saturation.

Is it a panacea to use retrograde warm cardioplegia? The retrograde cardioplegia protects only the left coronary artery supply systems, in case of right origin of the atrio-ventricular bundle artery; this is not protected adequately during the surgical procedure, and thus may also be an origin of postoperative conduction disturbance. 
Remote ischemic preconditioning (RIPC) induced by brief ischemia and reperfusion reduces myocardial injury in CABG surgery patients and improves ventricle function, proved by postoperative isquemic myocardial enzyme markers (Troponin I, Troponin T, pro-BNP) and hemodynamic measures. Volatile anesthetic agents can mimic ischemic preconditioning: delivery of $>15$ minutes of Sevoflurane or Desflurane for myocardium protection have the same or additive effect as RIPC.

Glucose-insulin-potassium (GIK) is a potentially useful adjunct to myocardial protection. Also high-dose insulin therapy protects by enhancing early metabolic recovery of the arrested heart during revascularization.

Non-diluted blood cardioplegia solution supplemented with L-arginine is associated with a significant decrease of myocardial lactate release after CXL and reperfusion during CABG surgery.

It is significant that reducing myocardial injury by using certain types of cardioplegia, adding protective substances, decreases the chance of arrhythmias and therefore pacing need.

The research for intraoperative PPM risk factors is important to improve outcomes.

(Table 6)

\begin{tabular}{|c|c|c|c|}
\hline Author & Surgery & $\mathbf{n}$ & Risk factors \\
\hline Lewis,1998 & REDO & 54 & $\begin{array}{l}\text { VS. Number of reoperations and degree of hypothermia } \\
\text { during CPB. }\end{array}$ \\
\hline Erdogan, 2006 & AVR & 465 & Total CPB and CXL time \\
\hline Goldman, 1984 & ALL & 5,942 & $\begin{array}{l}\text { VS especially, tricuspid. Poor myocardial protection. } \\
\text { Redo surgery. VS: aortic and tricuspid. Cold blood }\end{array}$ \\
\hline Del Rizzo,1996 & ALL & 3493 & $\begin{array}{l}\text { cardioplegia. } \\
\text { Postoperative IM }\end{array}$ \\
\hline Schurr, 2010 & AVR & 3534 & $\begin{array}{l}\text { Postoperatory RBBB. Associated procedures: CABG. } \\
\text { Aortic annulus size. CPB time .Redo. }\end{array}$ \\
\hline Merin, 2009. & ALL & 4,999 & AVR. \\
\hline Meimoun,2002 & MVR & 115 & A lesser systemic hypothermia during surgery. \\
\hline Huynh, 2009. & VAR & 207 & Cardiac arrest and dual valve surgery \\
\hline Elahi, 2005 & VAR & 782 & CPB > 100 minutes. CXL > 70 minutes. \\
\hline Totaro, 2000 & VAR & 124 & Continuous suture technique \\
\hline Baerman, 1987 & CABG & 93 & Number of bypassed arteries -CPB and CXL time. \\
\hline Gundry, 1987. & CABG & 468 & Blood cardioplegia \\
\hline Elahi, 1987. & VS & 2,392 & $\begin{array}{l}\text { Reoperations .Longer cumulative CXL times, multiple- } \\
\text { VS. }\end{array}$ \\
\hline
\end{tabular}

$\mathrm{ALL}=\mathrm{All}$ heart surgery; $\mathrm{AVR}=$ aortic valve replacement; $\mathrm{CABG}=$ coronary artery bypass grafting; $\mathrm{CPB}=$ cardiopulmonary bypass; $\mathrm{IM}=$ myocardial infarction; $\mathrm{MVR}=$ mitral valve repair o replacement; $\mathrm{REDO}=$ reoperation; $\mathrm{VS}=$ valve surgery $\mathrm{CXL}=$ aortic cross clamping.

Table 6. Intraoperative risk factors.

\section{What to do to minimize the risk of PPM}

It is necessary to minimize the risks of PPM, after a thorough analysis and validation of results trying to: 
Solve preoperative non-sinus rhythm as possible.

Improve metabolic status as possible.

Minimally invasive approach (MVR).

Do valve repair instead of replacement where possible.

Do an optimal myocardial protection during CPB.

Minimize hypothermia times when it is not necessary.

Reduce CPB and aortic CXL times.

Continuous normothermic blood cardioplegia.

Improve adequate reperfusion.

Interrupted sutures in valve replacement.

\section{Indications and estimated time for PPM implantation}

Several variables are considered to place a PPM as well as the appropriate time to do so. (Table 7)

\section{Variables considered to place PPM after cardiac surgery}

Conduction disturbance
Start TPM time
Persistence arrhythmia in time
Surgery type
Patient's hemodynamic and clinical status
Complications's longer stay

Table 7. Variables considered to place PPM after cardiac surgery

High degree atrioventricular block, sick sinus syndrome, symptomatic bradycardia, slow atrial fibrillation and bifasicular block are the most frequent causes for implantation.

Postoperative complete atrioventricular block is the most important predictor of pacemaker dependency, enabling early decision on permanent pacemaker implantation.

The cardiac surgery allows direct access to the heart and therefore the possibility of implanting in atrials and/or ventricles temporary epicardial electrodes.

Although the common problems of poor sensing or capture, dislodgement or retention exist. There is no best appropriate status criteria for wires removal. Decision for optimal time for PPM implantation after cardiac surgery is a controversial item and should be individualized for each patient. The mean postoperative day of pacemaker implantation varies from 5 up to 7 days. Nevertheless, we can find averages between 3 and 31 days. (Table 8) An early PPM placement enables early mobilization and facilitates hospital discharge.

Each individual patient is affected by several risk factors including surgery type, preoperative rhythm, postoperative conduction abnormalities, different QRS complex morphology, and onset TPM time of postoperative course.

To Glikson, the maximum waiting time is no later than the sixth and the ninth postoperative days for wide-complex and narrow-complex escape, respectively. (Glikson, 1997)

Because of the extreme variability in the evolution of these arrhythmias Heart Association leaves to the physician's choice to decide when is the best time for PPM implantation, although they recommend waiting for at least 7 days in cases of second grade and third grade AVB in adolescents or patients undergoing congenital disease surgery. 


\begin{tabular}{llc} 
Author & Surgery & $\begin{array}{l}\text { Time } \\
\text { (days) }\end{array}$ \\
\hline Schurr, 2010 & AVR & $4.4 \pm 3.8$ \\
Merin, 2009 & ALL & 5 \\
Berdajs, 2008 & MV & 4 \\
Glikson, 1997 & ALL & $6-9$ \\
Koplan, 2003 & VS & $8.4 \pm 5.8$ \\
Huynh, 2009 & AVR & $6.1 \pm 2.3$ \\
Dawkins, 2008 & AVR & 5 \\
\hline
\end{tabular}

$\mathrm{ALL}=\mathrm{All}$ heart surgery; $\mathrm{AVR}=$ aortic valve replacement; $\mathrm{CABG}=$ coronary artery bypass grafting; $\mathrm{MV}=$ mitral valve surgery; $\mathrm{VS}=$ valve surgery .

Table 8. Time elapsed between TPM and PPM placement, after cardiac surgery.

Prolonged immobilization from temporary pacing impedes patient recuperation and may increase the risk of pneumonia, deep venous thrombosis, and pulmonary embolism. Early pacemaker implantation may reduce morbidity and postoperative hospital stay.

\subsection{Valve surgery}

Waiting times to place a PPM in heart valve surgery are similar to other cardiac surgeries, unless combined with CABG and mitral valve repair; circumstances when it is prudent to wait for three or four more days for the spontaneous sinusal rhythm recovery (if it previously existed)

Hancock, 1988, advised permanent pacemaker implantation as soon as the third day in those patients with AVB after aortic valve surgery. For patients undergoing valve surgery, who develop complete AVB before the first postoperative $24 \mathrm{~h}$ and hold it for 48 hours, it is suggested to implement PPM before the first week.

Nevertheless, Zakhia Doueihi have observed that waiting for 10 days after surgery between 15 and $20 \%$ of valve patients with advanced AVB degree, spontaneously recover and do not require a permanent device. (Zakhia Doueihi, 1992)

The high percentage of cases with irreversible complete AVB in tricuspid valve replacement, along with difficulty of endocavitary pacemaker implantation after surgery has caused to take the usual attitude of implanting an electrode in the same surgery.

How much time should patients be monitored to expect appearance of arrhythmias after AVR? In the long-term monitoring (102 months) in survivors of AVR with a normal ECG, a $13.7 \%$ conduction disorders was reported, but only 1\% PPM was required. Another research analyses PPM requirement after artificial aortic valve replacement is because of $\mathrm{AV}$ complete block and atrial fibrillation with slow ventricular response. Since the 9th up to 196th month, all these patients remained in good general NYHA state with permanent stimulation, and in complete AV block disappeared 24 months after AVR.

\subsection{CABG surgery}

Pathological lesions in the left anterior descending coronary artery compromising flow in the first perforator that do not provide an adequate circulation produce localized damage and conduction disturbances after coronary artery bypass grafting. This can be predicted from the preoperative angiographic anatomy.

After heart surgery, 35\% of coronary patients with complete AVB and up to $70 \%$ of patients with sinus node disease are no longer dependent on the pacemaker over time. 
In a short series of Baerman, 1987, the recovery of sinus rhythm in patients implanted with pacemakers for complete AVB was $54 \%$.He also found that the third degree AVB appears in $4 \%$ of the patients and nearly all of them finally needed PPM.

\section{Epicardic pacemakers complications}

Intraoperatory epicardial electrodes are usually implanted on the anterior right ventricular muscle in areas without epicardial fat. It is an easily accessible area and it provides good pacing and sensing.

\subsection{Failure of ventricular sensing and capture}

Classic studies show that univentricular stimulation generates depolarization through multiple aberrant pathways in the unstimulated ventricle. Isolated right ventricular pacing reproduces the pattern of ventricular activation of left bundle branch block, so it has multiple deleterious effects. It may develop inter- and intraventricular left dyssynchrony, narrowing the left ventricular diastole, and an increasing relationship between diastolic times of both ventricles. All that has been said above precipitates a worse left ventricular filling, prolonged ventricular isovolumetric contraction-relaxation, lateral wall is contracted during diastole causing interventricular septal paradoxical movement. All these deleterious effects on left ventricular contractility and filling can be very harmful in the immediate postoperative period, especially in patients with systolic and/or diastolic ventricular dysfunction, with inotropic or intraaortic balloon pump dependency.

All these effects are pointing out that in certain patient groups postoperative epicardial biventricular pacing to improve cardiac output and postoperative course can be effective.

\subsection{Others complications}

These are bleeding from right ventricular laceration with tamponade, avulsion of a side branch from a saphenous vein coronary bypass graft, and perforation of the superior epigastric artery, gastric penetration, etc. They are emergency situations that put patient's life in danger, leading to urgent reoperation surgery, more days of mechanical ventilation and hospital stay, increasing mortality.

Removal of wires should be done under echocardiography control and in an operating room prepared for emergency reoperation.

\section{Other pacemaker uses for heart surgery}

\subsection{Atrial fibrillation}

Between the second and fourth postoperative day, postoperative atrial fibrillation has a variable incidence, about $30 \%$ for CABG surgery, $40 \%$ for valve surgery and $50 \%$ for combined surgery. It is an arrhythmia that is associated with hemodynamic instability, congestive heart failure, renal insufficiency, infection, neurologic injury and thromboembolism.

It is also associated with adverse outcomes and increased costs. Accordingly, therapy should be provided to prevent it. The assessment therapies do so is an area of active research with recent significant advances.

Multiple strategies are described to reduce incidence, most of them through drug treatment, primarily with beta blockers, amiodarone, magnesium, or combinations thereof. Except for magnesium in conventional doses, the others are not free of complications. 
Premature atrial extrasystole produces dispersion of atrial refractoriness and induces a heterogeneous anisotropic conduction, especially in regions near the coronary sinus and the triangle of Koch. (Figure 7) These regional differences between refractory periods and the prolongation resulting in atrial activation, are precisely the best substrate for the creation of re-entry that supports the initiation and perpetuation of atrial fibrillation. Atrial pacing may prevent the occurrence of arrhythmia.

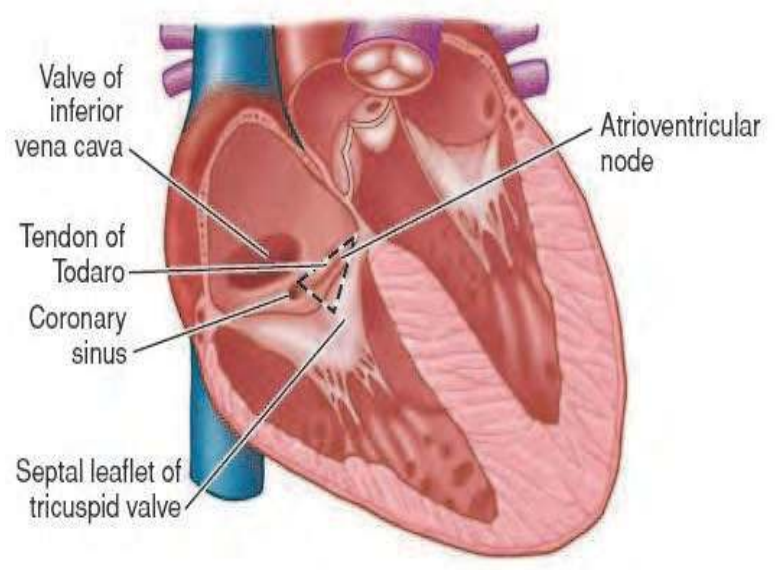

Fig. 7. Triangle of Koch, where the atrioventricular node lies.

During the 70's atrial pacing was not seen as a help for improving the cardiac output. Medical science is constantly changing day after day.

Two meta-analyses evaluated the atrial pacing prevention effect for postoperative atrial fibrillation. The findings analyses are quite similar. The biatrial and right atrial stimulation, at varying frequencies can reduce the incidence of postoperative atrial fibrillation from 2.6 to 1.8 times, respectively, while fixed frequencies only has proven effective in biatrial stimulation.Some studies agree that this therapeutic is safe and well tolerated, although to be effective should be combined with drugs. Biatrial mode pacing opens a promising new treatment opportunity.

\subsection{Others uses}

The problem with OPCAB is hemodynamic instability when heart is tilted for posterior's coronary arteries access. Decrease mean and systolic arterial pressure and increase left atrial pressure.

Several attempts have been proposed to improve this: Trendelenburg maneuver, right-side rotation (cardiac volume improve) of patient, $\beta$ blockers, etc.; but all these methods have their own complications. Even one-lung ventilation (left lung excluded) was proposed. Without ventilation oscillation, the surgeon would find a quiet field to do bypass grafts faster. It was a failure because the heart shifts to the bottom thoracic cavity.

Mechanical stabilization with a restraining device and a suction device for immobilization are ways to resolve this situation. 
In $\mathrm{OPCAB}$, the effect of atrial epicardial pacing improves ventricular function. It increases cardiac output and mean and systolic pressures, and decreases central venous pressures, resulting in better tolerance at the exposure maneuver.

\section{Conclusion}

During cardiac surgery the placement of temporary pacemaker is usually necessary, especially for weaning from $\mathrm{CPB}$. Epicardial electrode wires come out through the skin next to the incision. There are complications such as sensing and capture failures. Also during wire extraction trauma may occur. Predisposing factors for arrhythmia are pre- intra- and postoperative conduction disturbances, age $\geq 65$ years; valve surgery and those surgeries where there is manipulation around to the conduction system, and inadequate myocardial protection. When arrhythmia persists more than 7 days, the placement of a permanent pacemaker is advisable.

It is important to make the decision to implant a permanent pacemaker. This implies to take into account arrhythmia damage mechanisms, times, and probable reversibility.

All these points must be informed to patients.

\section{References}

[1] Ashida Y Ohgi S, Kuroda H, Ishiguro S, and col. Permanent cardiac pacing following surgery for acquired valvular disease. Ann Thorac Cardiovasc Surg. 2000 Jun;6(3):161-6.

[2] Baerman JM, Kirsh MM, De Buitleir M and col. Natural history and determinants of conduction defects following coronary artery bypass surgery. Ann Thorac Surg. 1987; 44: 150- 3.

[3] Bateman TM, Gray RJ, Raymond MJ, Chaux A, and col. Arrhythmias and conduction disturbances following cardiac operation for the removal of left atrial myxomas. J Thorac Cardiovasc Surg. 1983 Oct; 86(4):601-7.

[4] Batra AS, Wells WJ, Hinoki KW, and col. Late recovery of atrioventricular conduction after Pacemaker implantation for complete heart block associated with surgery for congenital heart disease. J Thorac Cardiovasc Surg.2003; 125: 1291- 3.

[5] Ben Ameur Y, Baraket F, Longo S, Annabi N and col. Conductive disorders following open- heart valvular surgery. Concerning 230 operated patient. Ann Cardiol Angeiol (Paris). 2006 Jun; 55(3):140-3.

[6] Berdajs D, Schurr UP, Wagner A, Seifert B and col. Incidence and pathophysiology of atrioventricular block following mitral valve replacement and ring annuloplasty. European Journal of Cardio-Thoracic Surgery Volume 34, Issue 1, July 2008, Pages $55-61$.

[7] Bethea BT, Salazar JD, Grega MA, Doty JR and col. Determining the utility of temporary pacing wires after coronary artery bypass surgery. Ann 2005 Jan; 79(1):104-7.

[8] Bolcal C, Emrecan B, Bingol H and col. Does combination of antegrade and retrograde cardioplegia reduce coronary artery bypass grafting-related conduction defects? Heart Surg Forum. 2006; 9:E866-70.

[9] Borracci R, Rubio M, Milani A and col. Abordaje transeptal para el reemplazo valvular mitral. Revista Argentina de Cardiología, VOL 78, No 5 / SEPTIEMBREOCTUBRE 2010, pp 400-404 
[10] Brazão A, Eugénio L, de Oliveira F, Antunes M. Surgery for acute type-An aortic dissection. Rev Port Cardiol. 1997 Jun; 16(6):525-32, 507.

[11] Bruschi G, De Marco F, Fratto P, Oreglia J and col. Alternative approaches for transcatheter self-expanding aortic bioprosthetic valves implantation: single-center experience. Eur J Cardiothorac Surg. 2011 Jun;39(6):e151-8.

[12] Coma Samartín R., Carbonell de Blas R.; Castaño Ruiz M. Estimulación cardiaca temporal. Estimulación tras cirugía cardiaca. Rev Esp. Cardiol. 2007; 7 (Supl G):5468.

[13] Cook DJ, Bailon JM, Douglas T and col. Changing incidence, type, and natural history of conduction defects after coronary artery bypass grafting. Ann Thorac Surg. 2005; 80: $1732-7$.

[14] Cooper JP, Jayawickreme SR, Swanton RH. Permanent pacing in patients with tricuspid valve replacements. Br Heart J. 1995; 73: 169-72.

[15] Crystal E, Connolly SJ, Sleik K and col. Interventions on prevention of postoperative atrial fibrillation in patients undergoing heart surgery: a meta-analysis. Circulation. 2002; 106: 75 - 80.

[16] Daoud EG, Snow R, Hummel JD and col. Temporary atrial epicardial pacing as prophylaxis against atrial fibrillation after heart surgery: a meta-analysis. J Cardiovasc Electrophysiol. 2003; 14: 127 - 32.

[17] Dawkins S, Hobson AR, Kalra PR, Tang AT and col. Permanent pacemaker implantation after isolated aortic valve replacement: incidence, indications, and predictors. Ann Thorac Surg. 2008 Jan; 85(1):108-12.

[18] Del Nido P, Goldman B. Temporary epicardial pacing after open heart surgery: complications and prevention. J Cardiac Surg 1989; 4: 99 - 103.

[19] Del Rizzo DF, Nishimura S, Lau C, Sever J, Goldman BS. Cardiac pacing following surgery for acquired heart disease. J Card Surg. 1996 Sep-Oct; 11(5):332-40.

[20] Dias RR, Mejia OA, Fiorelli AI, Pomerantzeff PM.Analysis of aortic root surgery with composite mechanical aortic valve conduit and valve-sparing reconstruction. Rev Bras Cir Cardiovasc. 2010 Oct-Dec; 25(4):491-9.

[21] Dimarakis I, Rehman SM, Grant SW, Saravanan DM, and col. Conventional aortic valve replacement for high-risk aortic stenosis patients not suitable for trans- catheter aortic valve implantation: feasibility and outcome. Eur J Cardiothorac Surg. 2011 Feb 21. Epub ahead of print.

[22] Do QB, Pellerin M, Carrier M, and col. Clinical outcome after isolated tricuspid valve replacement: 20-year experience. Can J Cardiol. 2000; 16: 489-93.

[23] Edwin F, Aniteye E, Tettey M, Sereboe L and col. Permanent complete heart block following surgical correction of congenital heart disease. Ghana Med J. 2010 Sep; 44(3):109-14.

[24] Elahi M, Usmaan K. The bioprosthesis type and size influence the postoperative incidence of permanent pacemaker implantation in patients undergoing aortic valve surgery. J Interv Card Electrophysiol 2006; 15:113-118.

[25] Elahi M, Lee D, Dhannapuneni RR. Predictors of permanent pacemaker implantation during the early postoperative period after valve surgery. Tex Heart Inst J. 2006; 33(4):455-7. 
[26] Eltchaninoff H, Prat A, Gilard M, Leguerrier A and col.Transcatheter aortic valve implantation: early results of the FRANCE (French Aortic National Core Valve and Edwards) registry. Eur Heart J. 2011 Jan; 32(2):191-7.

[27] Emlein G, Huang SK, Pires LA, and col. Prolonged bradyarrhythmias after isolated coronary artery bypass graft surgery. Am Heart J. 1993 Nov; 126(5):1084-90.

[28] Erdogan HB, Kayalar N, Ardal H, and col.Risk factors for requirement of permanent pacemaker implantation after aortic valve replacement. J Card Surg. 2006; 21: 211-5.

[29] Fan K, Lee KL, Chiu CS, and col. Effects of biatrial pacing in prevention of postoperative atrial fibrillation after coronary artery bypass surgery. Circulation 2000; 102: 755-60.

[30] Feldman S, Glikson M, Kaplinsky E. Pacemaker dependency after coronary artery bypass. Pacing Clin Electrophysiol. 1992; 15: 2037-40.

[31] Fernández P., Garro H., Pastori J., Chiale P. Indicaciones de implante de marcapasos definitivo en cirugía cardíaca. Revista del Conarec, Noviembre- Diciembre 2008 Año 24 - No97:415-417.

[32] Flack JE 3rd, Hafer J, Engelman RM, Rousou JA and col. Effect of normothermic blood cardioplegia on postoperative conduction abnormalities and supraventricular arrhythmias. Circulation 1992; 86(5 Suppl): II-385-92.

[33] Forlani S, Moscarelli M, Scafuri A and col. Combination therapy for prevention of atrial fibrillation after coronary artery bypass surgery: a randomized trial of sotalol and magnesium. Card Electrophysiol Rev. 2003; 7: 168-71.

[34] Fukuda T, Hawley R L and Edwards J E. Lesions of conduction tissue complicating aortic valvular replacement. Chest 1976; 69; 605-614.

[35] Gerstenfeld EP, Hill MR, French SN, Mehra R and col. Evaluation of right atrial and biatrial temporary pacing for the prevention of atrial fibrillation after coronary artery bypass surgery. J Am Coll Cardiol. 1999 Jun; 33(7):1981-8.

[36] Glikson M, Dearani JA, Hyberger LK and col. Indications, effectiveness, and long-term dependency in permanent pacing after cardiac surgery. Am J Cardiol. 1997; 80:1309-1.

[37] Goldman BS, Hill TJ, Weisel RD, and col.Permanent cardiac pacing after open-heart surgery: acquired heart disease. Pacing Clin Electrophysiol. 1984 May; 7 (3 Pt 1):367-71

[38] Gordon RS, Ivanov J, Cohen G, and col. Permanent cardiac pacing after a cardiac operation: predicting the use of permanent pacemakers. Ann Thorac Surg. 1998 Nov; 66(5):1698-704.

[39] Grande AM, Fiore A, Massetti M, Viganò M. Iatrogenic circumflex coronary lesion in mitral valve surgery: case report and review of the literature. Tex Heart Inst J. 2008; 35(2):179-83.

[40] Gregoratos G, Abrams J, Epstein AE, and col. Guideline Update for Implantation of Cardiac Pacemakers and Antiarrhythmia Devices -summary article: a report of the American College of Cardiology/American Heart Association Task Force on Practice Guidelines (ACC/AHA/NASPE Committee to Update the 1998 Pacemaker Guidelines). J Am Coll Cardiol. 2002; 40: 1703 -19.

[41] Gulielmos V, Kappert U, Eller M, Sahre H and col.Improving hemodynamics by atrial pacing during off-pump bypass surgery. Heart Surg Forum. 2003; 6(6):E179-82. 
[42] Gundry SR, Sequeira A, Coughlin TR, McLaughlin JS. Postoperative conduction disturbances: a comparison of blood and crystalloid cardioplegia. Ann Thorac Surg. 1989 Mar; 47(3):384-90.

[43] Habicht J, Scherr P, Zerkowski H, Hoffmann A. Late conduction defects following aortic valve replacement. J Heart Valve Dis 2000; 9:629 -32.

[44] Hancock EW. AV block after aortic valve replacement. Hosp Pract (Off Ed). 1988; 23: 4148.

[45] Haworth P, Behan M, Khawaja M, Hutchinson N and col. Predictors for permanent pacing after transcatheter aortic valve implantation. Catheter Cardiovasc Interv. 2010 Nov 1; 76(5):751-6.

[46] Holzhey DM, Shi W, Borger MA, Seeburger J, and col.Minimally invasive versus sternotomy approach for mitral valve surgery in patients greater than 70 years old: a propensity-matched comparison. Ann Thorac Surg. 2011 Feb; 91(2):401-5.

[47] Huynh H, Dalloul G, Ghanbari H, Burke P, and col. Permanent pacemaker implantation following aortic valve replacement: current prevalence and clinical predictors. Pacing Clin Electrophysiol. 2009 Dec; 32(12):1520-5.

[48] Imren Y, Benson AA, Oktar GL, Cheema FH and col.Is use of temporary pacing wires following coronary bypass surgery really necessary? (Torino). 2008 Apr; 49(2):2617.

[49] Jahangiri M, Laborde JC, Roy D and col. Outcome of patients with aortic stenosis referred to a multidisciplinary meeting for transcatheter valve. Ann Thorac Surg. 2011 Feb; 91(2):411-5.

[50] Jilaihawi H, Chin D, Vasa-Nicotera M, Jeilan M, and col. Predictors for permanent pacemaker requirement after transcatheter aortic valve implantation with the Core Valve bioprosthesis. Am Heart J. 2009 May; 157(5):860-6.

[51] Kikura M, Sato S. The efficacy of preemptive Milrinone or Amrinone therapy in patients undergoing coronary artery bypass grafting. Anesth Analg. 2002; 94: 22-30.

[52] Kim MH, Deeb GM, Eagle KA, and col. Complete atrioventricular block after valvular heart surgery and the timing of pacemaker implantation. Am J Cardiol. 2001; 87: $649-51$.

[53] Koplan BA, Stevenson WG, Epstein LM and col. Development and validation of a simple risk score to predict the need for permanent pacing after cardiac valve surgery. J M Coll Cardiol. 2003 Mar 5; 41(5):795-801.

[54] Lazzara RR, Park SB, Magovern GJ. Cardiac myxomas: results of surgical treatment. J Cardiovasc Surg (Torino). 1991 Nov-Dec; 32(6):824-7.

[55] Lewis JW Jr, Webb CR, Pickard SD, and col. The increased need for a permanent pacemaker after reoperative cardiac surgery. Thorac Cardiovasc Surg. 1998 Jul; 116(1):74- 81.

[56] Li L, Luo W, Huang L, Zhang W, and col. Remote preconditioning reduces myocardial injury in adult valve replacement: a randomized controlled trial. 2010 Nov; 164(1):e21-6.

[57] Limongelli G, Ducceschi V, D'Andrea A, Renzulli A and col. Risk factors for pacemaker implantation following aortic valve replacement: a single centre experience. Heart 2003 Aug; 89(8):901-4.

[58] Maisel WH, Rawn JD, Stevenson WG. Atrial fibrillation after cardiac surgery. Ann Intern Med. 2001; 135: 1061- 73. 
[59] Matthews IG, Fazal IA, Bates MG, Turley AJ In patients undergoing aortic valve replacement, what factors predict the requirement for permanent pacemaker implantation. Interact Cardiovasc Thorac Surg. 2011 Mar; 12(3):475-9.

[60] McLeod CJ, Attenhofer Jost CH, Warnes CA, Hodge D 2nd and col. Epicardial versus endocardial permanent pacing in adults with congenital heart disease. 2010 Sep; 28(3):235-43.

[61] Meimoun P, Zeghdi R, D'Attelis N, Berrebi A and col. Frequency, predictors, and consequences of atrioventricular block after mitral valve repair. 2002 May 1; 89(9):1062-6.

[62] Merin O, Ilan M, Oren A, Fink D and col. Permanent pacemaker implantation following cardiac surgery: indications and long-term follow-up. Pacing Clin Electrophysiol. 2009 Jan; 32(1):7-12.

[63] Mitchell LB, Crystal E, Heilbron B, Page P. Atrial fibrillation following cardiac surgery. Can J Cardiol. 2005; 21: B45-50.

[64] Mitchell LB. Prophylactic therapy to prevent atrial arrhythmia after cardiac surgery. Curr Opin Cardiol. 2007; 22: 18- 24.

[65] Molnár T, Farkas K, Palkó A, Eszlári E and col. Gastric penetration of epicardial pacemaker leads 8 years after cardiac surgery. Endoscopy. 2010; 42 Suppl 2:E273-4.

[66] Mosseri M, Meir G, Lotan C, et al. Coronary pathology predicts conduction disturbances after coronary artery bypass grafting. Ann Thorac Surg 1991; 51: 24852.

[67] Moya Mur J.; Oliva De Anquin E. Centella Hernández T. y col. Selección del mejor lugar de estimulación tras cirugía cardiaca evaluando la asincronía con strain tras diferentes estimulaciones. Rev Esp Cardiol.2010; 63:1162-70.

[68] Nardi P, Pellegrino A, Scafuri A, Bellos K, and col.Permanent pacemaker implantation after isolated aortic valve replacement: incidence, risk factors and surgical technical aspects. J Cardiovasc Med (Hagerstown). 2010 Jan; 11(1):14-9.

[69] Oter Rodríguez R, Montiel J, Roldán Pascual T, and col. Guías de práctica clínica de la Sociedad Española de Cardiología en marcapasos. Rev Esp. Cardiol. 2000; 53: 947 66. 10.

[70] Puskas JD, Sharoni E, Williams WH, Petersen R, and col. Is routine use of temporary epicardic pacing wires necessary after either OPCAB or conventional CABG/CPB? Heart Surg Forum. 2003; 6(6):E103-6.

[71] Raichlen JS, Campbell FW, Edie RN, Josephson ME and col. The effect of the site of placement of temporary epicardial pacemakers on ventricular function in patients undergoing cardiac surgery. Circulation.1984 Sep; 70(3 Pt 2):I118-23.

[72] Raza SS, Li JM, John R, Chen LY, and col. Long-Term Mortality and Pacing Outcomes of Patients with Permanent Pacemaker Implantation after Cardiac Surgery. Pacing Clin Electrophysiol. 2011 Jan 5. doi: 10.1111/j.1540-8159.2010.02972. Nov; 11(5):55660.

[73] Roten L, Wenaweser P, Delacrétaz E, Hellige G and col. Incidence and predictors of atrioventricular conduction impairment after transcatheter aortic valve implantation. Am J Cardiol. 2010 Nov 15; 106(10):1473-80.

[74] Scafuri A, Nardi P, Forlani S, Bassano C and col. Bentall-DeBono intervention: 8 years of clinical experience. Ital Heart J Suppl. 2000 Jun; 1(6):783-9. 
[75] Schurr UP, Berli J, Berdajs D, Häusler A and col. Incidence and risk factors for pacemaker implantation following aortic valve replacement. Interact Cardiovasc Thorac Surg. 2010 Nov; 11(5):556-60.

[76] Scrofani R, Carro C, Villa L, Botta M and col. Cardiac myxoma: surgical results and 15year clinical follow-up. Ital Heart J Suppl. 2002 Jul; 3(7):753-8.

[77] Scully HE, Armstrong CS. Tricuspid valve replacement. Fifteen years of experience with mechanical prostheses and bioprostheses. J Thorac Cardiovasc Surg. 1995; 109:1035 $-41$.

[78] Silvero M. Boullosa J. Implicaciones Anestesiológicas en el Síndrome de Carney.Revista Anestesia en México; Vol. 21 Nro 1 (Enero-Abril 2009) ,68-72.

[79] Sniezek-Maciejewska M, Małecka B, Bednarek J, Machejek J and col. Patients history following artificial aortic valve and pacemaker implantation. Przegl Lek. 2004; 61(6):718-21.

[80] Totaro P, Calamai G, Montesi G, Barzaghi C, Vaccari M. Continuous suture technique and impairment of the atrioventricular conduction after aortic valve replacement. J Card Surg 2000; 15:418-422.

[81] Tseng EE, Lee CA, Cameron DE, Stuart RS and col.Aortic valve replacement in the elderly. Risk factors and long-term results. Ann Surg. 1997 Jun; 225(6):793-80.

[82] Wisheart JD, Wright J E C, Rosenfeldt F. L, Ross J. K. Atrial and ventricular pacing after open heart surgery. Thorax 1973; 28:9-14.

[83] Yao YT, Li LH. Sevoflurane versus propofol for myocardial protection in patients undergoing coronary artery bypass grafting surgery: a meta-analysis of randomized controlled trial. Chin Med Sci J. 2009 Sep;24(3):133-41.

[84] Zakhia Doueihi R, Leloux MF, De Roy L, Kremer R. Permanent cardiac pacing for prolonged second and third degree atrioventricular block complicating cardiac valve replacement. Acta Cardiol. 1992; 47: 157 - 66.

[85] Zieroth S, Ross H, Rao V and col. Permanent pacing after cardiac transplantation in the era of extended donors. J Heart Lung Transplant. 2006; 25: 1142-7. 


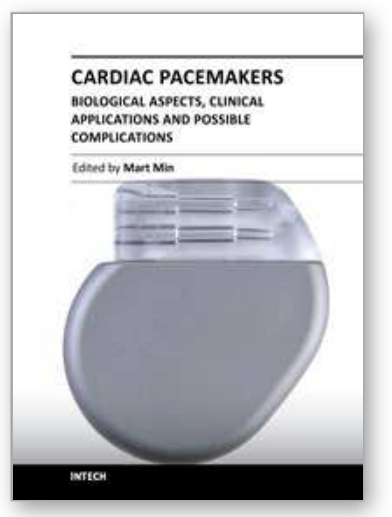

\section{Cardiac Pacemakers - Biological Aspects, Clinical Applications and Possible Complications}

Edited by Prof. Mart Min

ISBN 978-953-307-639-3

Hard cover, 194 pages

Publisher InTech

Published online 06, September, 2011

Published in print edition September, 2011

Clinical usage of artificial pacing dates back to 1958, when the battery powered cardiac pacemakers became available. Modern implantable pacemakers are the complicated electronic devices operating 10 years continuously without battery exchange. Though the development of devices is not a primary topic of the book, certain efforts towards developing of biologic pacemakers through tissue engineering and studying of cell synchronization are discussed. The main attention is paid to implementations of pacemakers in different medical situations oriented towards widening the clinical indications for implanting the cardiac pacemakers. New methods and devices in cardiac resynchronization therapy (CRT) have received particular attention. Placing of pacing electrodes has been treated soundly. Furthermore, emerging of complexities and complications in new clinical situations and other safety problems have been discussed thoroughly. The authors have derived the used information from their own clinical practice and experiences of their medical colleagues. These and other pragmatic features can be acknowledged as the most valuable asset of the book.

\section{How to reference}

In order to correctly reference this scholarly work, feel free to copy and paste the following:

Silvero Miriam, Browne Leonardo and Solari Gabriel (2011). Pacemaker Following Adult Cardiac Surgery, Cardiac Pacemakers - Biological Aspects, Clinical Applications and Possible Complications, Prof. Mart Min (Ed.), ISBN: 978-953-307-639-3, InTech, Available from: http://www.intechopen.com/books/cardiacpacemakers-biological-aspects-clinical-applications-and-possible-complications/pacemaker-following-adultcardiac-surgery 1

\section{INTECH}

open science | open minds

\section{InTech Europe}

University Campus STeP Ri

Slavka Krautzeka 83/A

51000 Rijeka, Croatia

Phone: +385 (51) 770447

Fax: +385 (51) 686166

www.intechopen.com

\section{InTech China}

Unit 405, Office Block, Hotel Equatorial Shanghai

No.65, Yan An Road (West), Shanghai, 200040, China 中国上海市延安西路65号上海国际贵都大饭店办公楼 405 单元

Phone: $+86-21-62489820$

Fax: +86-21-62489821 
(C) 2011 The Author(s). Licensee IntechOpen. This chapter is distributed under the terms of the Creative Commons Attribution-NonCommercialShareAlike-3.0 License, which permits use, distribution and reproduction for non-commercial purposes, provided the original is properly cited and derivative works building on this content are distributed under the same license. 